\title{
Developing Post-Occupancy Evaluation using Value Engineering in the Higher Education Buildings
}

\author{
Abdullah Badawy Mohammed \\ Lecturer, Architectural Engineering Department, \\ Faculty of Engineering, Fayoum University, \\ Egypt.
}

\begin{abstract}
The research studies the evaluation of the higher education buildings after operating and using because the periodic maintenance works that are being conducted on these buildings, which are being carried out without reviewing the functional performance or following a scientific methodology the post-occupancy evaluation. Therefore, the research aims to conclude and formulate a methodology for developing and improving post-occupancy evaluation and trying to increase its efficiency after linking with value engineering to improve development plans. Consequently, during applying the postoccupancy evaluation framework that will depend on value engineering to benefit from the functional analysis stage as the most significant stages for analysing and improving functions. Then the field and practical study of the deduced methodology that will be investigated by the maintenance and development teams and specialists to measure and evaluate the significance of the methodology elements and the appropriateness of its mechanism in developing the higher education buildings. In addition to it will be applied in these projects as a practical study to show the new potentials of the deduced methodology. Therefore, the deduced methodology will improve the functional performance of the buildings and the educational spaces and be involved in development plans.
\end{abstract}

Keywords: Post-Occupancy Evaluation (POE); Functional Performance; Value Engineering (VE); Functional analysis; Higher Education.

\section{INTRODUCTION}

Periodic maintenance works were being implemented in higher education buildings with their design problems without activating the role of post-occupancy evaluation (POE) for functional performance and operational efficiency. Also, reviewing the educational process quality, what it will need to modify and develop in functions and spaces, and studying what it will meet from needs and requirements. These all because most architects have not used a scientific methodology to improve the functional performance of buildings during their review and evaluating in general. In addition, there is not the specialists' team to review the building performance and its functions besides the maintenance team so as not to implement maintenance works at buildings with their problems.

POE has provided enormous potentials for improving the building performance [1]. POE has evolved to fill the gap in the traditional process of the building that consists of planning, programming, design, construction, and occupancy of the building [2]. Vischer [3] has proposed that POE is used to determine the building defects, formulate the design and construction criteria, improve performance measurements, and decrease life-cycle costs; consequently, identifying design errors that could lead to increase the maintenance and operating costs, and clarifying the design objectives. Preiser [4] presented an architectural review of POE to building performance assessment as a personal perspective to the better understanding of the conceptual and theoretical basis for POE and the building performance evaluation. The term 'evaluation' includes the concept of values; the person has to determine clearly whose values are involved, and what he needs to compare benchmarks and findings. Although informal and subjective evaluations of the environment are conducted, and systematic evaluations that use the explicitly stated performance criteria with what they measure the performance of buildings are compared, they are the origin that is more recent. Significant efforts of early evaluation were a response to critical problems that are faced in institutions; some of them were because of the built environment [5]. In all cases, the users assess their environment based on predefined quality standards and feature. Different researchers have proposed and developed the prototypes or methodologies that were focused on the performance of facilities of educational buildings. Their methodologies involved, the tools for gathering information such as a questionnaire, walk-throughs, focus group discussions, interviews, and observations [6,7]. Preiser and Nasar [2] discussed the questions about the POE future, its viability, effectiveness of costs, and benefits for all stakeholders. They concluded with the recent project examination was reported in the book "Designing for designers" used to distribute technology to systematically evaluate the performance of the seventeen global contemporary architecture schools. Göçer et al [7] provided a review of the improvements in the building performance evaluation and introduced a new method of POE to complete the missing link in the building design process. Existing studies were reviewed to understand the possible reasons for the missing link of "the building performance feedback ". POEs can be started as a research, as case studies, or to meet the feedback needs of a specific building and related activities. All of them an analytical approach that measures how occupants feel about their environment through questionnaires, interviews, and observations, then evaluates how many occupants like and how environmental conditions 
improve the design. In addition, the primary building evaluation tools have focused on the incremental improvements of the environment. Mustafa [8] developed the customized questionnaires where an array of performance indicators had developed to address various performance attributes and elements that contribute to the overall performance. Tookaloo and Smith [9] presented the reports on the research team that had developed a plan to improve the quality of campus facilities through the POE exercise on a project was recently built. Through the POE of the University of Utah, was utilized the process of focus group interviews represent the users, subsequent survey, and demonstrated the POE theory and practice in the higher education and learning environment. Through the feedback on the evaluation from users, and the ability of university and planning departments more prepared to deal with future project planning. In addition, the university buildings will be closer to meet the needs of the user and maintenance. In addition, Mustafa [8] addressed the building performance revision based on the experts' rating that measures using a score based on the quality of the various building attributes were mentioned previously. Attributes were related to the building performance had listed from the survey of the experts' rating and each attribute rating on the relative performance elements that refer to the scale value of building performance indicators.

From the previous literature, the researcher finds that POE is the procedural stages and steps subject to the personal experiences and experiments or the team that will perform it; these will affect the quality of results, recommendations, and the functional performance even after executing and reviewing the recommendations. Consequently, POE needs scientific techniques and methodologies were accredited in the performance analysis of functions during the early POE framework stages and steps [2]. Many modern technologies and innovative scientific methods through which can improve the performance and reduce the effort, cost, and time with the most efficiency and best quality [10]. From these techniques and methodologies "Value Engineering" (VE) which has efficiently helped the designer during the study of the performance of the building by the functional analysis [11]. This what research attempts to achieve through proposing a practical methodology based on the VE, which forms the basis for a POE in practice and applying by the functional analysis that carries out the research team.

\section{THE RESEARCH PROBLEM}

The main problem is that most engineers responsible for the maintenance and renewal of the higher education buildings have not used a scientific methodology during the stages of checking and analysing the functional performance of these buildings and their elements to improve, support, and raise the operation efficiency them that depend on POE fundamentally.

\section{THE RESEARCH AIM AND OBJECTIVES}

The aim of this study is to deduce and formulate the improvement methodology of the functional performance of higher education buildings by the post-occupancy evaluation (POE) after linking with the value engineering (VE). The objectives of this study are:
- To demonstrate and activate POE by studying and analysing in terms of the concept, importance, and framework;

- To shed light on the VE role that supports the functional analysis process;

- To link the POE and VE through the work plan for activating the role of the functional analysis to measure and evaluate the performance of the building;

- To access the fundamental indicators and elements of the deduced methodology by the functional performance measurement concept, and determine its standards and fields;

- To conclude and formulate a mechanism and a methodology for improving the functional performance of the higher education buildings after linking POE and VE; and

- To evaluate the efficiency and appropriateness of the deduced methodology by introducing the methodology elements and steps in questionnaires for proving the importance of its mechanism in applying on higher education buildings to develop plans, also increasing the functional performance efficiency of the buildings.

\section{RESEARCH METHODOLOGY}

The methodology depends on the inductive approach in studying and analysing the POE concept in terms of the importance and the performance measurement fields, the POE stages, and the VE role to support the project value. The analytical approach will study and analyse the relationship between POE and VE to conclude the VE work plan that supports POE. Then the role of the functional analysis will be activated to measure and evaluate the performance of higher education buildings as the most important stages of VE. Consequently, the study will demonstrate the functional performance measurement concept to access the deduced methodology indicators and elements. Eventually, the study will deduce and formulate the methodology POE of higher education buildings, which is based on VE to access the required functional performance. Also, the applied approach to evaluating the methodology by introducing its elements and mechanism in the questionnaires to measure its importance and appropriateness to evaluate and develop the functional performance of this type of buildings. Then the differences in the results of applying in the case study after linking with VE toward the best improvement of the functional performance.

\section{POST - OCCUPANCY EVALUATION (POE)}

\section{A. The Concept of Post - Occupancy Evaluation}

Depending on the previous studies, it has been known as the process of evaluating and reviewing the buildings that have already used and occupied. A POE is a later stage of the sequential design processes (planning, design, construction, operation, and evaluation) $[7,10]$. It has been also known as a research methodology that uses the field research and various measurement technologies to evaluate the building in all aspects for the benefit of its users, their integrity and to ensure their good performance within the building [12]. This 
methodology gathers the information about the building in a regular frame; thus supporting the design decisions by avoiding previous mistakes and knowing the reality and magnitude of problems according to their priorities [6,13].

\section{B. The Importance of POE}

Knowing what has achieved from the needs and requirements, and providing a vision of the results and consequences of the correct decisions that have been taken as a beginning to formulate all of this information is a base for preparing buildings with a higher efficiency [9]. Due to the characteristics of the higher education buildings and their distinguished nature from other buildings. Therefore, the possibility of dividing the design problem into a number of partial problems, and using appropriate techniques to solve partial problems $[14,15]$.

\section{The Practical model of the POE framework}

It explains the executive procedures for evaluating the performance of the building after using by the periodic integrative model that has a structure that contains three components: (Methods of measuring [10,16] - Information and databases [15] - sets of standards [8,12]).

\section{The Levels of POE}

The POE can be conducted through three levels of effort during the evaluation, namely: (1) first level (indicative); (2) second level (investigative); and, (3) third level (diagnostic) [4]. These levels due to several factors are [12,15]: (a) the importance of the project; (b) time; (c) the sources of information; (d) persons that conduct the research; (e) the depth of the evaluation; (f) stakeholders' aims; and, (g) costs. Each of these levels has three main stages, are:

\section{E. The Framework of Conducting the POE Process}

The framework consist of three stages; each of them has three steps $[7,10,6,13,14,17]$ :

\section{1) The first stage: preparing of $P O E$}

This stage includes administrative and research activities aimed at preparing and coordinating POE before starting. This happens in three sequential steps: (1) surveying and studying the feasibility; (2) planning the resources; and, (3) planning for the research.

\section{2) The second stage: implementing of $P O E$}

This stage aims to gather and analyse the information and ensure its quality through the harmonisation among the various tasks and the actual coexistence of the built environment because it adds to the researcher a deeper understanding through three sequential steps: (1) gathering information from the site; (2) following up and managing collected information; and, (3) analysing the collected information.

\section{3) The third stage: applying of $P O E$}

Documenting the results and proposals. Then the decisions are made based on the proposals. Eventually, reviewing of results of applying the recommendations to verify from achieving the expected and desired benefits through three sequential steps: (1) gathering the results in a report; (2) proposing the recommendations; and, (3) checking the results of applying the recommendations. After the concept of POE has been studied, it is also necessary to shed light on VE as a scientific methodology that supports applying and improving the POE.

\section{THE VALUE ENGINEERING ROLE IN ARCHITECTURE}

Value Engineering (VE) is one of the most important administrative methods, the most modern accreditation in the developed world, and an analytical study by a multidisciplinary team on a product, a project, or a service to define and classify the functions that it performs. The aim of $\mathrm{VE}$ is the better implementing for those functions, at lower overall costs, and all of the above together through innovative alternatives without damaging the basic requirements based on the basics and principles of the balance between the three elements of the project are. These elements are [18,19,20,21,22,23]: (1) performance: the purpose for which the product has been manufactured; (2) quality: it means the amount of achieving the wishes of the special beneficiary, and aesthetic values and the durability entered into it; and, (3) total cost: the amount of what was spent money, effort, and time. This means that improving the quality, upgrading the functional performance, and reducing the cost leads to the higher value according to the following equation: Value Measurement $=($ Performance + Quality $) /($ Total Cost $)$; this methodology has proven a high possibility of solving the problems based on its ability in "Functional analysis"[21]. All this has enabled it to improve the architectural work and generate creative ideas, upgrade the level of projects are designed or implemented [8,20,22].

\section{THE RELATIONSHIP BETWEEN THE POE} AND VE

$\mathrm{VE}$ is a functional engineering was designed to investigate the performance of functions. In addition, it performs its role in a better manner or at a lower cost where its goal is to not only reduce costs, while its goal is to minimize the waste as long as the function does well and the goals that help to the development [10]. An illustrative example of the relationship between the POE and VE as an approach of reducing costs, and delete some parts while VE has based on the analysis of the functions. Then proposing alternatives that lead to the purpose at lower cost, and these alternatives may be different from what in the original design [9].

\section{THE WORK PLAN OF VE THAT SUPPORTS} AND IMPROVES POE

It is composed of nine steps. These steps follow a logical sequence Fig. 1 [19,22,23,24]: 


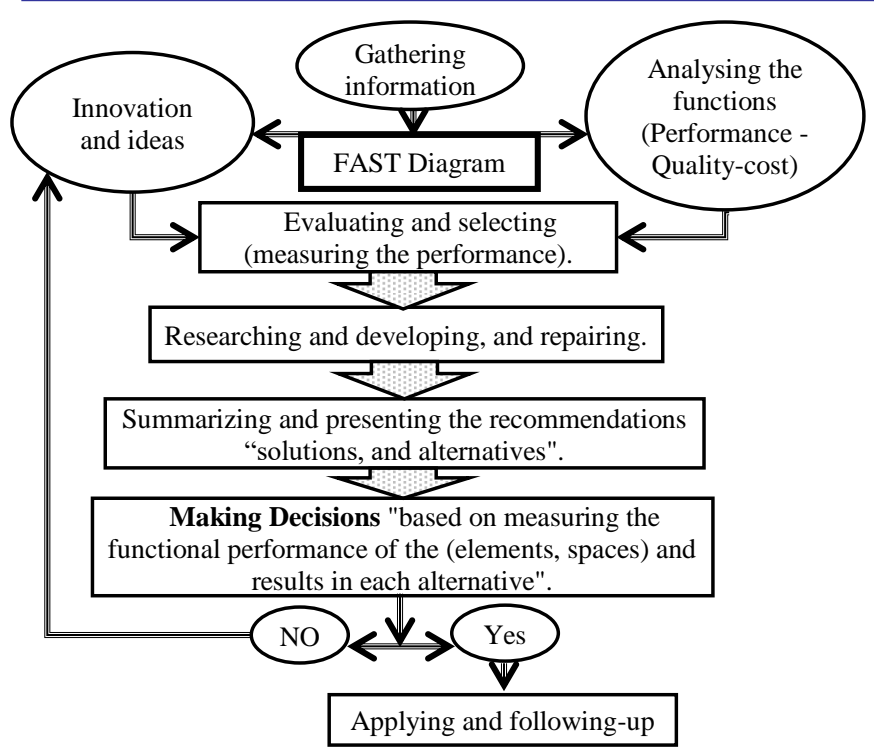

Fig. 1. The work plan of VE that supports the POE.

\section{THE FUNCTIONAL ANALYSIS AS THE IMPORTANT STAGE OF VE AND ITS RELATION TO THE POE}

Analysing the functions of the spaces and elements of the educational building has a particular nature because of the clear differentiation of the activities. From these activities, the education, sporting, literal, practical, musical, and technological, and their need for the separation, assembly, and distribution, which the project team from various disciplines carry out them. At this stage, that links VE with POE, the functions of the project are defined, classified well, and the relationships among these functions are realised. By analysing the functions that are required to achieve and improve, and by defining goals, needs, and requirements [22,25]. Then VE looks for the basics and fields of the performance efficiency, and measuring and evaluating it through defining the quality standards, and finally seeks to get it at the minimum possible costs that are the life cycle cost [26]. In other words, POE is the process of evaluating the building based on systematic methodologies as VE after it has been occupied. The functional analysis steps, are [21,25]: (1) defining, identifying the functions, and their purpose; (2) classifying the functions by $\mathrm{VE}$, there are four categories of functions (basic - secondary - required secondary unwanted); (3) linking all functions together by "FAST Diagram" that helps to clarify the relationship among them; and, (4) selecting the functions that can be improved. These improvements depend on the bases of performance as measuring, comparing, evaluating, and feedback. Finally, the project team can turn the functions into ideas and proposals that achieve the objectives of these functions, and reduce costs.

In order to achieve the close link between VE and POE; the design process must be a two-dimensional process. The first dimension; following-up the stages of the design process from the stage of the beginning of understanding and determining the problems then the design relationships and finding solutions. Then the second dimension; following-up the decisions that have periodic cycles that occur during all phases of the building life cycle [26].

\section{THE RESPONSIBLE AUTHORITIES IN THE HIGHER EDUCATION BUILDINGS}

Reviewing the performance in the higher education buildings walks in two-directions:

\section{A. In the first direction}

The engineer administration responsibility under the supervision of the ministry of higher education to achieve the objectives of the quality of the educational process and the development of new studies programs with what they need for buildings, spaces, and functional elements that the ministry is always reviewing them.

\section{B. In the second direction}

The engineer administration implements periodic maintenance works under the observation of the ministry of higher education are reviewing the quality of the performance of spaces and functional elements. With what it needs from the development works by forming a team of specialists in cooperation with the administration and ministry.

\section{USING POE IN MEASURING AND EVALUATING THE BUILDING PERFORMANCE}

The building performance can be defined as the behaviour of the elements of the building in the natural and artificial conditions in time and meeting users' needs in a general understanding: occupant's needs and the surrounding community [12,2]. Increasing expectations and demands of the built environment and occupants' comfort have led to induce improvements in tools and techniques of measurement in buildings [25]. Many techniques are available to measure efficiency and carefully the performance of the studied building. Although there is no defined methodology to POE, and the selected techniques should be decided based on the required needs and objectives of conducting the evaluation $[2,10,6]$.

\section{THE FUNCTIONAL PERFORMANCE MEASUREMENT CONCEPT}

Measuring the functional performance allows providing the clearest indicators of the real and objective potential of the built environment and taking advantage of the outputs of this measurement to modify, check the building, and develop its performance, in addition to preparing new buildings more efficient. This all means that when there is a comparison of the requirements (objectives) and standards (the measurement instruments); this is the concept of performance that is the governing link to measure the success or failure of the buildings. The performance depends on what buildings achieve from their users' needs. The performance concept depends on four standards in studying any element or space, are [15]: 
A. Measurement: the use of some elements and spaces decreases and increases with technological development and the social, political, and economic conditions;

B. Comparison: among the existing models of similar buildings and reviewing and evaluating their performance, any of them the highest performance and more efficient;

C. Evaluation: it depends on the standards, design principles, references, building codes, and qualitative evaluation criteria; and

D. Feedback: from the executive experiences, measurements, evaluation, follow-up, and previous designs to develop and update databases of the functional performance.

In addition, three fields of evaluating the performance must be defined [12]: (1) the scale of the built environment (a part of space, a complete space, or sets of spaces); (2) the users of the built environment (individuals, groups, or institutions) [14]; and, (3) the elements of performance (technical, functional, or behavioural) [16].

\section{THE PERFORMANCE IMPROVEMENT METHODOLOGY OF THE HIGHER EDUCATION BUILDINGS BY POE FROM THE VE PERSPECTIVE}

From the above in the relationship between the POE and VE; and after linking and reconciling between them. It can be concluded and formulated a mechanism and a methodology to improve the functional performance of higher education buildings this methodology is:

A. The First Stage: Preparing and Planning of POE

1) Surveying and studying the feasibility;

2) Forming a team from specialists;

3) Planning the resource and timetable for the work team; and

4) Planning for the research (identifying sources of data and evaluation criteria).

B. The Second Stage: Implementing of POE

1) Starting on the process of gathering information from the building;

2) Following up and managing the collected information;

3) Analysing the collected information by VE depending on the functional analysis: (a) analysing the project into a set of the elements;(b) determining the function of each element accurately; and, (c) sorting elements by the function type if a main, a secondary that cannot be neglected, a secondary that can be neglected, or a harmful that must be treated;

4) Evaluating each element within the project in terms of the efficiency of performance, quality, and cost. Also, investment in terms of: (a) its characteristics (aesthetic, functional, and durable); (b) the characteristics of the site; and, (c) the characteristics of the neighbouring environment;
5) Discussing the alternatives for each element in terms of possibilities: (deleting it, improving its work, changing its place, changing the method of its implementing, or replacing it with a range of alternatives that are less expensive, higher quality, and more efficient). The discussion of alternatives will base on: (a) the compatibility with the latest technologies; (b) the development cost; (c) the application easiness; (d) the required time for application; (e) the expected benefit of the application; (f) the efficiency of the functional performance; $(\mathrm{g})$ easiness of future maintenance; (h) savings in the consumption; and, (i) formation and aesthetic aspects;

6) Reassembling the elements after selecting the alternative each of them; and

7) Evaluating the project alternatives as a whole to calculate the full value of them in terms of performance, quality, and cost.

C. The Third Stage: Applying of POE

1) Gathering the results in a report;

2) Proposing the recommendations; and

3) Checking the results of the implemented recommendations.

\section{EVALUATING THE EFFICIENCY OF THE} DEDUCED METHODOLOGY

The analytical and practical study of the deduced methodology, also its efficiency will be evaluated by its elements and mechanism will be introduced in questionnaires to the study community. Therefore, the importance of the deduced methodology elements and the application mechanism appropriateness for this type of the projects (higher education buildings) will be measured to raise their functional performance efficiency.

\section{A. The Objective of the Deduced Methodology Efficiency Evaluation}

If there are other elements or steps, the study will add and link them to the deduced methodology, or it will need to reformulate.

\section{B. The Used Method of Measuring and Verifying the Questionnaire Results}

Questionnaires and interviews with the specialists in the development, maintenance, and design of higher education buildings; will be conducted [26]. They will be asked to provide their views to indicate the influence level of the deduced methodology elements and steps. The research will use the Likert scale to estimate or rate the importance, namely: $5=$ critical, $4=$ important, $3=$ somehow important, $2=$ less important, and $1=$ not important. The cut-off mean value is 2.50 and above that represents the significant, and will affect ( $P$-value) $[27,28]$. The study results will provide the significant and rank indication of the critical elements and steps. The questionnaires will be analysed and reviewed by the program (SPSS) to conduct (One-Sample $t$-test) (righttailed) to identify and rate the significance of the elements, and (two-tailed) to arrange the steps. 


\section{Defining the Sample Members}

The number of persons that have worked in the buildings of the universities was chosen to conduct the field study, according to their specialisation in the development and construction works. The number of sixty persons is as follows (twenty-six of architects, thirteen from civil engineers, eight from the construction management, eight from the engineer administration of the university, and five specialists in the design; taking into consideration that they have worked in various university buildings [27,28,29].

\section{The Results of the Study (practical Study)}

The results of the questionnaire indicate the importance degree of the methodology elements that have been checked in terms of if they will be re-arranged, replaced, or new elements will be added; also, the appropriateness of the deduced methodology mechanism was checked by:

- The value of ( $P$-value) of the element will be reviewed if its value was lowest, the element will become more significant or important, and vice versa;

- The value of ( $P$-value) of the element will be reviewed if its value was lowest, the element or step will become the closest in its rank, but if it was equal;

- The value of arithmetic mean will arrange them where the element or step had the highest mean will become the closest in its rank, but if it was equal; and
- The researcher will arrange them according to the standard deviation where the element or step that had the lowest standard deviation will become the closest in its rank.

The results of the questionnaire indicate that (P-value) of each element is less than 5\% (the significance level). These will confirm that all the deduced methodology elements are important, and the implementation mechanism steps of the deduced methodology are appropriate. Therefore, the elements and steps were distributed during seven stages instead of three stages by the results of the field study. Table 1 shows the statistical analysis results as the importance and rank of the stages and elements; and Fig. 2 illustrates the application mechanism.

TABLE I. TABLE 1. THE STATISTICAL ANALYSIS RESULTS ON THE IMPORTANCE OF THE ELEMENTS AND THEIR RANK ACCORDING TO THE IMPORTANCE OF EACH STAGE AND ITS STEPS

\begin{tabular}{|c|c|c|c|c|c|c|}
\hline Stage & $\mathbf{O}$ & The elements & $P$-value & $\begin{array}{l}\text { Mean } \\
\text { Rank }\end{array}$ & $\begin{array}{l}\text { Std. } \\
\text { Dev. }\end{array}$ & Std. Err. M. \\
\hline \multirow{2}{*}{ D. } & 1 & Surveying and studying the feasibility. & 0.000 & 1.067 & 0.2515 & 0.0324 \\
\hline & 2 & Forming a team from the specialists. & 0.000 & 1.933 & 0.2515 & 0.0324 \\
\hline \multirow{2}{*}{$\frac{\dot{\Xi}}{a}$} & 3 & Planning the Resource and Timetable for the work team. & 0.000 & 3.000 & 0.0000 & 0.0000 \\
\hline & 4 & Planning for the research. & 0.000 & 4.150 & 0.3600 & 0.0464 \\
\hline \multirow{2}{*}{ 兽 } & 5 & Starting the process of gathering information. & 0.000 & 4.833 & 0.4184 & 0.0540 \\
\hline & 6 & Following up and managing the collected information. & 0.000 & 6.050 & 0.2197 & 0.0283 \\
\hline \multirow{4}{*}{ 㟥 } & 7 & Analysing the collected information by the VE. & 0.000 & 6.950 & 0.2197 & 0.0283 \\
\hline & 8 & Analysing the project into a set of elements & 0.000 & 8.050 & 0.2197 & 0.0283 \\
\hline & 9 & Determining the function of each element accurately. & 0.000 & 9.050 & 0.3872 & 0.0500 \\
\hline & 10 & Sort elements by the function type. & 0.000 & 9.950 & 0.3872 & 0.0500 \\
\hline \multirow{2}{*}{ 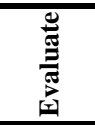 } & 11 & $\begin{array}{l}\text { Evaluating each element within the project in terms of performance, quality, } \\
\text { and cost. }\end{array}$ & 0.000 & 10.950 & 0.2197 & 0.0283 \\
\hline & 12 & Discussing the alternatives for each element. & 0.000 & 12.017 & 0.1290 & 0.0166 \\
\hline \multirow{2}{*}{$\begin{array}{l}\frac{0}{0} \\
\text { อัे } \\
0\end{array}$} & 13 & Reassembling the elements after selecting the alternative for each one. & 0.000 & 13.117 & 0.3724 & 0.0480 \\
\hline & 14 & $\begin{array}{l}\text { Calculating and evaluating the full value of project alternatives as a whole } \\
\text { (performance - quality - cost). }\end{array}$ & 0.000 & 13.900 & 0.3991 & 0.0515 \\
\hline \multirow{3}{*}{$\frac{2}{2}$} & 15 & Gathering the results in the report. & 0.000 & 15.017 & 0.2906 & 0.0375 \\
\hline & 16 & Proposing the recommendations. & 0.000 & 15.983 & 0.2906 & 0.0375 \\
\hline & 17 & Reviewing the results of the implemented recommendations. & 0.000 & 16.933 & 0.2515 & 0.0324 \\
\hline \multicolumn{7}{|c|}{$P$-value: The significance level and the element value less than $(5 \%)$ is important. } \\
\hline \multicolumn{7}{|c|}{ Mean of Rank: It has been depended in ranking the steps of applying the methodology. } \\
\hline \multicolumn{7}{|c|}{$\begin{array}{l}\text { Std. Deviation :The elements or steps that have a lower standard deviation. The difference in views about the element is less, and its value is closer } \\
\text { to its rank in the steps of its application mechanism. }\end{array}$} \\
\hline
\end{tabular}




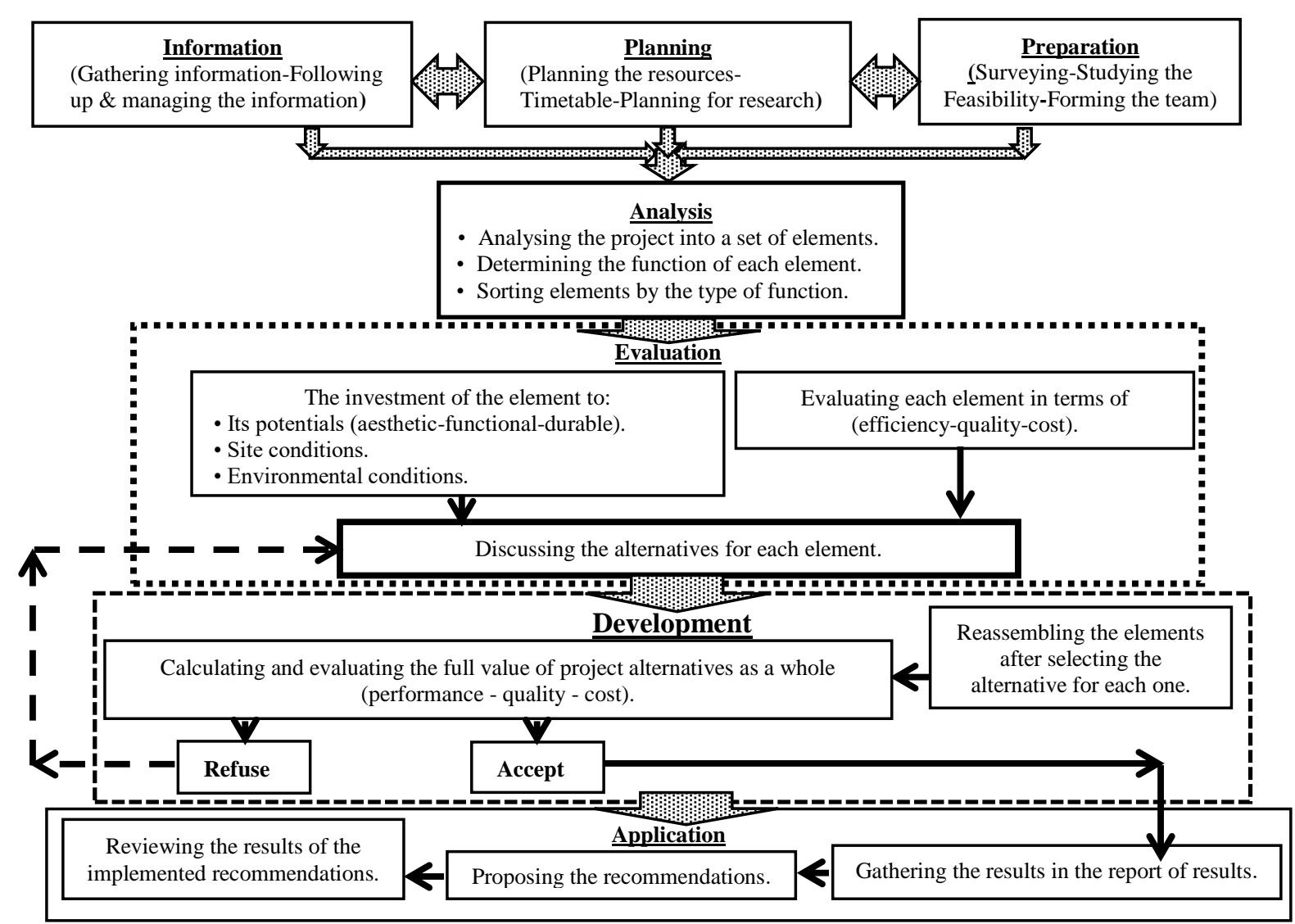

Fig. 2. Illustrates the steps and stages of the methodology to improve the functional performance of the higher education buildings from the perspective of VE.

\section{APPLYING THE DEDUCED \\ METHODOLOGY TO THE \\ ARCHITECTURE BUILDING OF THE \\ FACULTY OF ENGINEERING (THE OTHER FLOORS FOR THE GENERAL \\ ADMINISTRATION OF THE FACULTY)}

The POE framework was applied before linking with VE and after linking with VE. While investigating the studied building and using the stage of the information gathering, analysis, and evaluation; the deduced methodology has reached the following objectives are: to redistribute and reemployment for (functions to spaces after redistributing the spaces exactly for each use, the spaces of students' project stores, and areas of service spaces). In addition, to take advantage of the repeated spaces, spaces were not used, and the closed spaces and external spaces in the corridors to show projects. Also, to provide (spaces of new uses in line with the new needs of the educational and service process that did not take into consideration previously, innovative technology services that generate income to develop the architecture department itself and meet the needs of student activities, and the staff rest for members). Consequently, during the stage of the development and application, the study proposed the alternatives to improve the functional performance, which will help to access the best improvement proposal. Fig. 3 shows the proposal of linking POE with VE that indicates the main differences in the results and outputs where the results become more efficient and benefit from the building potentials. Therefore, the functional performance will be better as shown in Table 2 . 


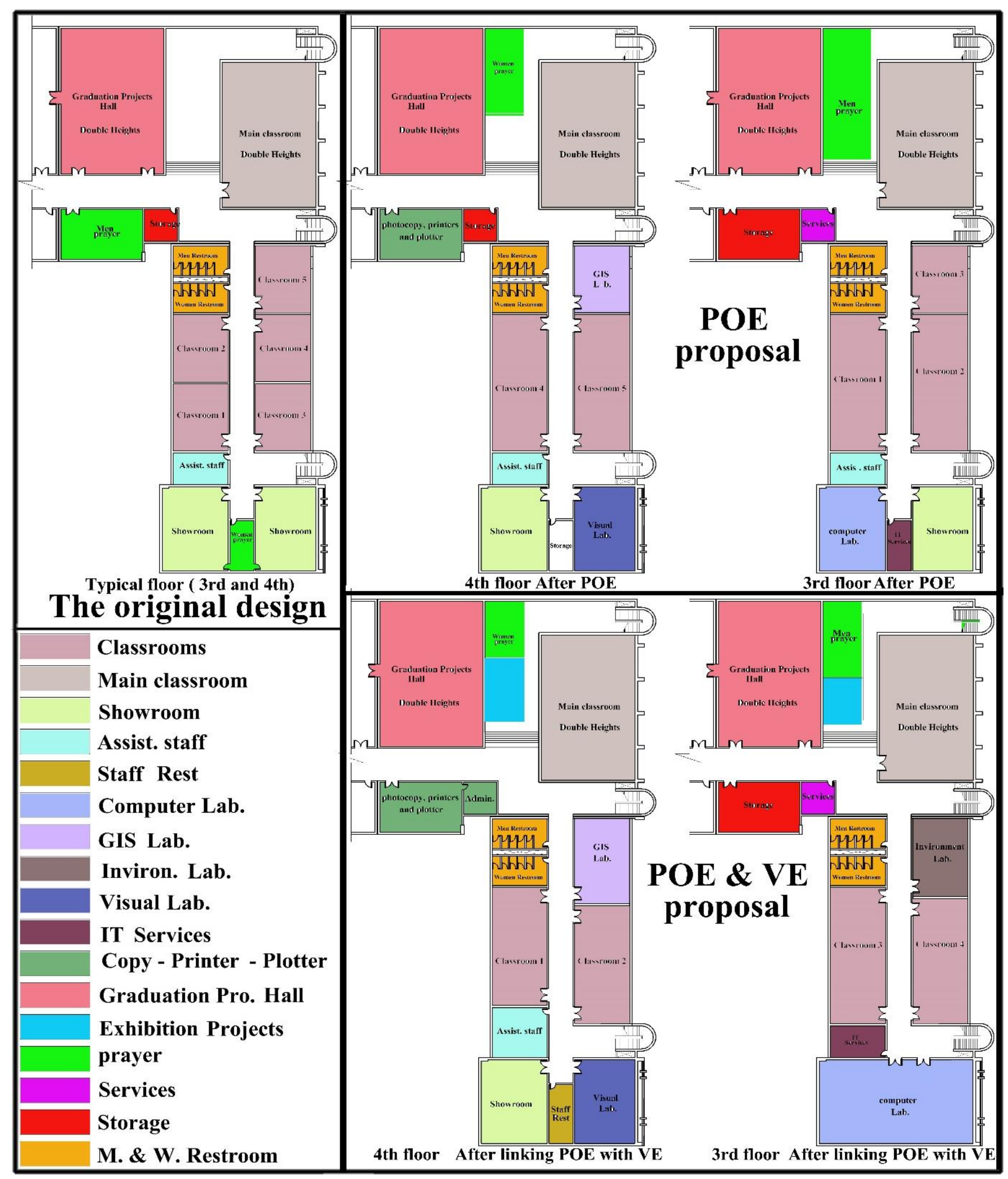

Fig. 3. Shows the variations between the original plans of the studied building floors, the POE proposal two plans, and the proposal two plans after linking POE with VE 
Table 2. The differences in the results of developing and improving after applying POE on the studied building floors before and after linking with VE

\begin{tabular}{|c|c|c|}
\hline Assessment & POE proposal & POE \& VE proposal \\
\hline No. of stages. & Three stages. & Seven stages. \\
\hline No. of steps. & Nine Steps (Three Steps per stage). & Seventeen steps (distributed during seven stages). \\
\hline $\begin{array}{l}\text { The } \\
\text { implementati } \\
\text { on stage. }\end{array}$ & $\begin{array}{l}\text { 1) less detailed and fewer step; } 2 \text { ) analysing information } \\
\text { depending on the experts' views; and, 3) solving the } \\
\text { problems, and trying to meet new requirements. }\end{array}$ & $\begin{array}{l}\text { 1) It was more detailed and clarified; 2) the collected information was analysed } \\
\text { by the deduced methodology; 3) the functional analysis stage of VE was used } \\
\text { for classifying functions and it was more sensitive with areas and zoning; and; } \\
\text { 4) the element was evaluated in terms of quality, performance, and cost. }\end{array}$ \\
\hline $\begin{array}{l}\text { The } \\
\text { application } \\
\text { stage. }\end{array}$ & $\begin{array}{l}\text { 1) proposing the solutions based on the team's view } \\
\text { without depending on a clear mechanism; } 3 \text { ) verifying } \\
\text { the access to results and expected benefits based on the } \\
\text { feasibility study; 2) Reviewing the actual application } \\
\text { results, whether it conforms to expectations or there are } \\
\text { large differences that need to be reviewed and know } \\
\text { reasons; and, 3) the proposed modifications were few } \\
\text { also insufficient to solve problems and meeting } \\
\text { requirements for the most appropriate operation. }\end{array}$ & $\begin{array}{l}\text { 1) re-assembling the elements in several proposals, evaluating them and } \\
\text { choosing the most quality in the performance; 2) the preliminary evaluation of } \\
\text { the project performance after selecting the most appropriate alternative before } \\
\text { applying; 3) reducing the large differences among expectations and application } \\
\text { results; and, 4) proposals and alternatives to the solution were numerous and } \\
\text { gave several proposals that led to changes in the performance and development } \\
\text { of functions and unused opportunities, and a new look at the building potentials. }\end{array}$ \\
\hline The results. & $\begin{array}{l}\text { The change is noticeable, but at lower rates and the } \\
\text { differences were accepted. }\end{array}$ & $\begin{array}{l}\text { The change is noticeable and strong in main differences in functions, their areas, } \\
\text { zoning and maximum exploitation of the building. }\end{array}$ \\
\hline
\end{tabular}

\section{DISCUSSION}

This deduced methodology has numerous potentials to analyse and develop the building performance and elements because it has depended on an organised mechanism to reach the best performance quality at the services and the building functions based on:

- Activating the functions analysis role by the VE to improve the functional performance of the project elements because of the VE is considered from the protective methods at these stages and procedures;

- Close collaboration and good coordination among the participators, specialists, and stakeholders as a way to ensure that the new methodology of POE will succeed by concentrating on the particular priorities of the project due to the interest variance;

- Participants in POE should drill down into the key aims or results that agreed at the stage of preparing and should be linked to the previous aims of design;

- Rearranging the elements and steps of the deduced methodology in Seventeen steps (distributed during seven stages) instead of three stages depending on the field study has made it more sensitive and accurate to handle the existing building status as inputs and have a more effective effect to improve the project performance and its elements as outputs, as Fig. 3 shows the difference between the proposals before and after linking with VE; and

- The results have reached a significant difference in outputs that are more efficient and benefiting from the building potentials, which improved the functional performance.

The concept of functional performance has been the governing tool to measure the success or failure of projects; the performance depends on the degree or level of the project that meets its users' needs, purpose, and objectives.
When evaluating a new building, the aim is to learn from its operational experiences by its evaluating, modifying, and improving. Then taking advantages and experiences to apply in future buildings; also, increasing its efficiency and productivity, and preferably the building operates for a period of not less than one year before POE.

Using the deduced methodology to evaluate and develop types of other buildings after occupancy; this methodology needs restructuring and reviewing at each type of buildings to be confident and confirmed in the accuracy of results and proposals, also defining shortages if the team finds and takes them into account in the future projects.

Taking into account the previous experience of specialists and experts in dealing with buildings. The specialists have indicated that the current operation of the construction industry does not encourage the improvement of the building over time; also, POE is established on continuous learning and improvement in the long-term.

The design of future buildings should also take into consideration:

- Characteristics and parameters that will determine the performance efficiency of the buildings in proportion to the degree of users' satisfaction such as functional, behavioural, and technical. Because of the indicators and its attributes related to the performance of the building have a powerful relationship with the levels of users' satisfaction;

- The importance to follow the VE in the initial stages of projects, and giving information that can be used in the future in the implementation of similar projects; in addition, the design where the ability to the change is easier and at any other time;

- Buildings are becoming more intelligent and adaptively responsive to the changing environmental conditions; 
consequently, needing for feedback of real-time data is increasing; therefore, making the use of the technical expertise within the university and the engineering department where the time should be allowed for this in POE; and

- The application mechanism importance to improve the functional performance of the building in terms of the investment value, maintain the building in the case that satisfies its occupants and enable the building to perform its functions.

The applied study has shown that the deduced methodology can reduce and control the occurrence of large differences among improvement objectives, expectations, and actual results of the studied building. Also, benefiting of the international experiences and experiments; taking into consideration the local conditions and progress in line with the era spirit.

\section{CONCLUSION}

The research has presented a method and a methodology that through can increase the POE application process efficiency of higher education buildings in the analysis stage for functions that depend on the VE. In addition, it can support and improve the outputs, results, and recommendations of this evaluation that will improve the quality of the functional performance of the building and its functional elements. These all by the practical demonstration of the performance measurement concept, also its standards and fields are defined to access the indicators and elements of the concluded methodology that has affected the applying method of the POE steps and stages. In addition, it makes POE more accurate and detailed after linking it to the work plan of VE. The quality and efficiency of the deduced methodology were tested and evaluated through presenting it in questionnaires and interviews for specialists in the field of higher education buildings as the maintenance, development, and implementation works in universities and faculties. The results supported and confirmed the importance and appropriateness of the deduced methodology. Then the practical application on the architecture building of the engineering faculty, and the vital differences in the results and proposals were shown toward the best development and improvement after linking VE.

In addition, POE plays an essential role in strategic planning, building management and it can be considered from the building life cycle necessities. Therefore, POE can treat shortage appearances because it allows conducting the strategic evaluation of the current performance without stopping the building.

The building performance evaluation of the most important issues toward sustainability, also the new proposals are investigated and evaluated so that the results are valuable, credible, and do not depend on the absolute view of specialists, but in the narrowest limits and possibilities participating all new methodologies.

\section{REFERENCES}

[1] D.S. Watt, Building pathology: Principles and practice, John Wiley \& Sons, 2009

[2] W. Preiser, J. Nasar, Assessing-building performance: Its evolution from post-occupancy evaluation, Int. J. Archit. Res. 2 (2008) 84-99. doi:10.1073/pnas.0703993104.

[3] J. Vischer, Post-occupancy evaluation: A multifaceted tool for building improvement, Learn. From out Build. A State-of-thePractice Summ. Post-Occupancy Eval. (2002) 23-34.

[4] W.F.E. Preiser, Building performance assessment-from POE to BPE, A personal perspective, Archit. Sci. Rev. 48 (2005) 201-204. doi:10.3763/asre.2005.4826.

[5] A.O. Ilesanmi, Post-occupancy evaluation and residents satisfaction with public housing in Lagos, Nigeria, J. Build. Apprais. 6 (2010) 153-169. doi:10.1057/jba.2010.20.

[6] M. Riley, N. Kokkarinen, M. Pitt, Assessing post occupancy evaluation in higher education facilities, J. Facil. Manag. 8 (2010) 202-213. doi:10.1108/14725961011058839.

[7] Ö. Göçer, Y. Hua, K. Göçer, Completing the missing link in building design process: Enhancing post-occupancy evaluation method for effective feedback for building performance, Build. Environ. 89 (2015) 14-27. doi:10.1016/j.buildenv.2015.02.011.

[8] F.A. Mustafa, Performance assessment of buildings via postoccupancy evaluation: A case study of the building of the architecture and software engineering departments in Salahaddin University-Erbil, Iraq, Front. Archit. Res. 6 (2017) 412-429. doi:10.1016/j.foar.2017.06.004

[9] A. Tookaloo, R. Smith, Post Occupancy Evaluation in Higher Education, 2015. doi:10.1016/j.proeng.2015.08.470

[10] E. Attia, A. G. Atman, R. A. Riad, Towards a Methodology for Evaluating Public Buildings from the Point of View of Value Engineering. Journal of Engineering Sciences, Faculty of Engineering, Asyut University, Egypt, 42 (2014) 784-797.

[11] W. Chen, S. Liao, A job-plan based performance evaluation for construction value engineering study, J. Chinese Inst. Eng. 33 (2010) 317-333. doi:10.1080/02533839.2010.9671620

[12] R. Hay, F. Samuel, K.J. Watson, S. Bradbury, Post-occupancy evaluation in architecture: experiences and perspectives from UK practice, Build. Res. Inf. 46 (2018) 698-710 doi:10.1080/09613218.2017.1314692

[13] P. Morrison, Post Occupancy Evaluation of the Sheffield Internationa College, University of Sheffield, 2008 (2008).

[14] K. Adeyeye, P. Piroozfar, M. Rosenkind, G. Winstanley, I. Pegg, The impact of design decisions on post occupancy processes in school buildings, $\quad$ Facilities. $31 \quad$ (2013) 255-278. doi: $10.1108 / 02632771311307142$.

[15] R. Fulford, C. Standing, Construction industry productivity and the potential for collaborative practice, Int. J. Proj. Manag. 32 (2014) 315-326. doi:10.1016/j.ijproman.2013.05.007.

[16] D. Yan, W. O'Brien, T. Hong, X. Feng, H. Burak Gunay, F. Tahmasebi, A. Mahdavi, Occupant behaviour modelling for building performance simulation: Current state and future challenges, Energy Build. 107 (2015) 264-278. doi:10.1016/j.enbuild.2015.08.032.

[17] J. Halbe, J. Adamowski, E. M. Bennett, C. Pahl-Wostl, K Farahbakhsh, Functional organization analysis for the design of sustainable engineering systems, Ecol. Eng. 73 (2014) 80-91. doi:10.1016/j.ecoleng.2014.08.011

[18] R. Rachwan, I. Abotaleb, M. Elgazouli, The Influence of Value Engineering and Sustainability Considerations on the Project Value,

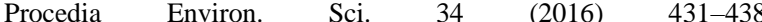
doi:10.1016/j.proenv.2016.04.038.

[19] I. Ciocan, C. Onutu, Analysis and value engineering applied in building restoration proposed methodology, Adv. Eng. Forum. 21 (2017) 596-601. doi:10.4028/www.scientific.net/AEF.21.596.

[20] A.E.D. El-Alfy, Design of sustainable buildings through Value Engineering, J. Build. Apprais. 6 (2010) 69-79. doi:10.1057/jba.2010.14

[21] J. Borza, FAST Diagrams: The Foundation for Creating Effective Function Models, Trizcon 2011. (2011) 1-10.

[22] A. Olatokun, E. Olatokun, C. Pathirage, Importance of knowledge capturing (KC) in the design briefing process in the construction industry, (2015). http://usir.salford.ac.uk/35626/. 
[23] A.J. Chavan, Value engineering in construction industry, Int. J. Appl. or Innov. Eng. Manag. 2 (2013) 18-26. doi:10.17485/ijst/2015/v8i32/87285.

[24] A. Chougule, A.K. Gupta, S. Patil, Application of Value Engineering Technique to A Residential Building - Case Study, Int. J. Innov. Res. Adv. Eng. 1 (2014) 115-118.

[25] R. Lawrence, C. Keime, Bridging the gap between energy and comfort: Post-occupancy evaluation of two higher-education buildings in Sheffield, Energy Build. 130 (2016). doi:10.1016/j.enbuild.2016.09.001.
[26] S. V. Russell-Smith, M.D. Lepech, R. Fruchter, Y.B. Meyer Sustainable target value design: Integrating life cycle assessment and target value design to improve building energy and environmental performance, J. Clean. Prod. 88 (2015) 43-51. doi:10.1016/j.jclepro.2014.03.025.

[27] A. Singh, B. Singh, Procedure of Research Methodology in Research Studies, Eur. Int. J. Sci. Technol. 3 (2014) 79-85.

[28] H. Coolican, Research methods and statistics in psychology. Psychology Press, 2017.

[29] C. Dawson, Practical Research Methods, India, New Delhi, UBS Publishers' Distributors, 2002. 